\title{
Global Water Dances: A Model for Global Justice and Community Agency
}

\author{
全球水之舞：一种全球正义和社区机构的模式 \\ Karen Bradley ${ }^{1}$, Marylee Hardebergh ${ }^{2}$, Natasha Alhadeff-Jones ${ }^{3}$, \\ Vannia Ibarguen ${ }^{1}$ \\ ${ }^{1}$ Laban/Bartenieff Institute of Movement Studies, US \\ ${ }^{2}$ Global Site Performance, US \\ ${ }^{3}$ Sunkhronos Institute, Switzerland
}

\begin{abstract}
Global Water Dances is a biannual global event that draws on Rudolf Laban's movement choirs, indigenous practices, creative pedagogy, social neuroscience, and community dance to address local and global concerns about water. This article highlights some of the discoveries and best practices the authors have noted and developed over the 10years of the project. Beginning with a conference on Laban and Ecology at Schumacher College in Devon, England, in 2008, the project has evolved from over 50 sites to over 160 sites in 2019. The authors share some of the stories from around the globe and discuss what has been learned regarding local wisdom and ritual, the value of finding common ground, the need for human connection, and the value of dance practices and dance education in developing shared agency, purpose, and social inclusion.
\end{abstract}

Keywords: Global Water Dances, global justice, community, agency

\section{摘要}

全球水之舞是一项一年两次的全球活动，它借鉴了鲁道夫.拉班的动作合唱、本土 实践、创意教学法、社会神经科学和社区舞蹈，以解决本土与全球水资源的 关切议题。这篇文章强调了作者在该项目 10 年来提出并发展的一些发现和最佳实践。 从2008年在英国德文郡舒马赫学院举行的拉班与生态学会议开始，该项目已经从50 多个地点发展到2019年的160多个地点。作者分享了一些来自全球各地的故事，也讨论 了收获的经验，涉及本土智慧和仪式、寻找共识的价值、人类对联结的需求，以及舞蹈 实践和舞蹈教育在发展共享的机构、目标和社会包容的价值。

关键词: 全球水之舞, 全球正义，社区，机构

We soon got the impression, which was reinforced by our occasional audiences, that we should show our compositions to the public, for nearly everyone who watched us was stimulated into joining in. Meanwhile, our plays had developed into small choir-works. One of the first was Dawning Light, in which we experienced the change from stepping in subdued sadness to the awakening of the revitalizing capacity which is dormant in the body. I emphasize "experienced" and not "presented" because at this stage we had 
no wish to show or convince an audience-although later on a presentation style emerged effortlessly and without our doing. We were solely concerned with experiencing in ourselves and in togetherness the increased vigour of the spiritual-emotional-physical forces which are united in dance. Why? Because we were drawn to it, we benefited from it, and we were inspired by it.

—Laban, 1975

\section{Background}

In 2008, at a celebration of Laban's 50th anniversary of leaving the planet permanently, a group of dancers and Laban experts decided to explore Laban's relationship with the planet he had left. The dozen or so who traveled to Schumacher College in Dartington, Devon, UK, were already well versed in the theories he had developed primarily for single movers but were relatively unfamiliar with the group work. And none had deeply explored Laban's particular relationship with Mother Nature that he had developed toward the end of his life.

Over the course of three days, while the rain fell endlessly, the participants moved, reflected, drew, notated, and discussed the relationships among dancing and stewardship, agency, and community. At the end of the three days, those present formed intentions to carry the work forward, specifically in creating a global, participatory dance around the theme of water.

\section{Ascona to Schumacher}

In 1912, Rudolf Laban was invited to develop a summer program in a village called Ascona, near the Swiss-Italian border, on Lake Maggiore. The nearby Mount Verita (the Mountain of Truth) had become a destination for intellectuals and anarchists, painters, and dancers alike. Martin Green (1986), in his book The Mountain of Truth, describes the why of the program Laban was invited to create:

At the end of the nineteenth century, intellectual Europe became preoccupied with the problem of its own unhappiness, malaise, or-to use Freud's word-Unbehagen. The favorites of this rich and powerful civilizationthe economically and educationally privileged, the most intelligent and imaginative-felt themselves to be unhappier than more primitive peoples. All over Europe...the Germans and German-speaking...were moving faster than other peoples to grasp the glittering prize of progress. (p. 1)

The Asconans created a destination devoted to organicity, community, and creativity. Laban's approach to dancemaking was not formulaic or based in traditional dance styles or vocabulary but was emergent and communally derived. The language that emerged from the explorations was based in the ways that the human body moved naturally and in varying degrees of flow. Environmental space was also important and the spatial constructs Laban began to explore came from natural forms. 
The movement choir structure that developed at Ascona was both spontaneous and devised, with individual contributions from the dancers. Some of the dancers were trained in traditional forms of ballet and/or folk dance, and some were simply interested in movement, and thus, a mélange of vocabulary and styles became the foundation of what was to become modern dance, the modern dance of middle Europe.

The structures that were used to organize the dancers also came from ancient and contemporary dance practices: circles, processions, proscenium presentations, and a variety of group formations that were both inclusive and presentational.

Eventually, Laban led the development of a notation system that stood in for verbal vocabulary so that movement experiences and creations could be generated and, eventually, recorded. The notation was also used to create, disseminate, and rehearse dance events over distances, since the outline of the notation score provided allowed for groups to practice their sections locally. A movement choir could therefore be choreographed so that anyone could participate, based on movement unrelated to a particular dance style of genre. Groups could then come together and share their sections. These choirs would culminate in a unified choreography that was constructed, spontaneous, and invoked common ground.

While we, Bradley and Hardenbergh, plus others, were at the retreat at Schumacher College, Hardenbergh shared a DVD of a project she had recently completed, One River Mississippi. Hardenbergh, who had extensive experience creating movement choirs, developed the idea of a dance that went along the entire Mississippi River (2350 miles) from Itasca, MN, to Plaquemines Parish, LA, in order to illustrate to the participants and audience the full impact of the river in its entirety.

Inspired by the idea of creating dances across distance in support of increasing perception of both global and local concerns, the group at Schumacher developed the beginnings of the idea that became Global Water Dances.

\section{Setting an Intention}

We knew we wanted to use the power of dance as the medium to send a message about the environment. At Schumacher College, we experimented with different aspects of the environment: the soil, air quality, and then decided that water would be the most universal aspect of the environment since all humans depend on water for life. Our intentions were to gather dancers from around the globe to share an awareness about water issues. We wished to work closely with environmental organizations to help further their local efforts. We imagined a worldwide environmental participatory performance event highlighting the necessity and healing powers of water.

We intended to provide interactive learning activities and advance the causes of awareness, accountability, and conscientious caretaking. Movement is something we share with all humanity. It is a universal language; a way to embody knowledge and insight and to embrace others in performance across the globe.

Before launching in 2011, we thought we would have 15 to 20 places participating in a global section that was designed through suggestions of movement phrases from the early participants. We hoped the shared movement for the third and fourth sections 
of the dances would be so simple that anyone who had the wish to participate, could participate. We were surprised when we had over 50 sites registering.

Keeping the message simple and focusing on the movement and building community resonated with the people who came in during those early days. We learned from the participants that they needed clarity and guidance, but not rules.

\section{Enter the Internet}

The steering committee for the project emerged from those who were at Schumacher College for the three-day symposium in 2008. Since we were composed of people from Germany, Canada, and the USA, we started primarily using emails to interact and exchange ideas. Skype was a little less than five years old when we realized that we could have bi-weekly meetings via Skype, and eventually, Zoom.

All planning has taken place online since 2009. The New York and Germany contingent worked on the choreography together via Skype and came up with a choreography for the global section, using suggested phrases of movement from participants. The Minneapolis member created the four simple moves for the audience participation section IV; these were shown to the steering committee and voted on. She gathered a group of friends to videotape them doing the four simple movements, and that was put onto our website.

We simply could not have carried out this worldwide effort without the internet. On the website, choreographers can download the music for the global section III and the video instructions. We also made publicity tools available via the website.

Compared with even just a few years earlier, we were able to utilize the internet for choreographers to upload their videos and send them to us. It is rather humorous to look back 12 years, when uploading a 25-minute video would take all night, even with the most advanced transfer methods available at the time. With one of our sites in Africa, the video actually had to be sent via a cultural attaché of the embassy and brought back as a videotape to the United States.

We have become aware of both the opportunities and the limitations of the internet. Certainly, space shrinks, but we became aware that time also shrinks, because we are all operating on at least two different time sequences: those of our everyday lives and work and that of the global differences in time zones, seasonal time changes, and the various approaches to time globally. For example, while we regularly give deadlines for signing up, for submissions, etc., they are followed inconsistently, at best. Time shrinks for us, but not necessarily for others. And part of what we have learned is that these differences are fine and that it is we who can adjust.

\section{The Structure}

Marylee's piece, One River Mississippi, provided a simple four-part structure that we adopted and adapted for Global Water Dances. The first part, the opening, is a ritual, a welcoming, a spiritual summoning, often by indigenous and local officiants. The second part is a created and performed dance about a local water issue. The choreography is by 
a local dancemaker, preferably with music from a local composer. The third segment is the dance that everyone does, to the same music. It is a connector of the parts, of the concerns, of the celebrations, of all of us, around the globe. And the fourth section is a short series of movements that everyone, audience, and performers alike, can do together.

Each of these sections serves a particular purpose in bringing communities together. The opening ritual calls the people together for the common goal of witnessing and engaging with what is to come. The far-ranging themes of the local dance works have allowed us all to learn about each communities' issues, to hear the stories, and to understand the challenges we all face. The third section allows the performers to join with the dancers around the world as a part of a global movement choir, promoting the idea that no community is alone in their concerns, challenges, or engagement with water. And the fourth, participatory section, brings the audience into community intention, motivating everyone to listen, learn, and act.

The use of quotidian movement figures largely in all four sections; we have noticed this is so even in the local dances (section II). The dances that are created are generally not feats of virtuosity. They tend to be thoughtful and often powerful reckonings with the issues at hand, using accessible movement vocabularies. The third section contains dance structures and patterns that are recognizable and resonant: circles, processions, and vignettes. Even when the dancers are organized in a proscenium-like setting (where the dancers and the audience face each other), there is the sense that the audience is a part of the dance too.

\section{Discovering Harms}

Each time the project happens, the world is in a slightly different state as regards water stewardship. In the first few years, the stories of environmental racism and degradation were not as front-and-center as was the celebration of water itself. By the third and fourth time the project occurred (2015 and 2017), the use of plastics and concerns about climate change dominated the site dances. Awareness of corporate greed, especially in relation to water quality and access for indigenous communities, has emerged as a primary theme to be addressed in recent years.

Examples of the increasing awareness of harms done include the following:

- Flint, Michigan: In 2017, the Flint community came together for their first-ever site of Global Water Dances. The Flint Youth Ballet had participated in community engagement events for over 25 years, but the 2017 group had not yet had the opportunity for community engagement. Global Water Dances came at the perfect time for the curriculum as well as a chance for the students to communicate their anger, fear, and hope during the Flint water crisis, which started in 2014 when the drinking water source for the city of Flint was changed from Lake Huron and the Detroit River to the Flint River. Due to insufficient water treatment, lead leached from the lead water pipes into the drinking water, exposing over 100,000 residents. 
- Shubenacadie River, Nova Scotia: Alton Gas proposed to create salt caverns in order to store natural gas underground, with the expressed intention to build more. The creation of these caverns would result in huge quantities of highly concentrated salt brine, which the company planned to dump down the Shubenacadie River. There are multiple fundamental problems with this project and the processes through which it was approved. Alton Gas Storage LP and the Nova Scotia government failed to adequately consult local Mi'kmaq communities, as demonstrated through a Supreme Court of Nova Scotia decision. Furthermore, it is a demonstration of the inadequacies of the current Indigenous consultation and environmental decision-making processes. Alton Gas threatens water in the construction, operation, and decommissioning stages and specifically would cause disastrous consequences for the Shubenacadie River and to all those who depend on it. At full operation, Alton Gas would be releasing approximately 10 million liters of brine (3,170 tonnes of hard salt) into the Shubenacadie River system each day.

- Bwaise, Uganda: Dancers from the Kawempe Youth Center of Kampala, Uganda, performed in 2019 to underline the importance of clean drinking water. Site leader, Lennie Kleinen, focused on waterborne diseases, such as cholera and typhoid. Bwaise is one of Kampala's largest urban slums. The people of Bwaise face housing, drainage, water, and sanitation issues daily. The area has severe flooding after heavy rains, causing outbreaks of cholera and typhoid. Bwaise residents have been relying on often polluted underground water streams for everyday domestic use. Bwaise does not have a piped water system. During the performance, the Kawempe Youth Center dancers combined traditional dances with contemporary techniques. Wearing traditional dress, the performers carried clay water pots as a medium through which they could communicate their message. The event was held near a centrally located, heavily polluted body of water, where thousands of people pass by every minute.

\section{Neuroscience of Social Connection}

We believe that human beings grow through and toward connection. The path of human development is through movement to increasingly differentiated and growth-fostering connection.

\section{-The Complexity of Connection: Writings from the Stone Center's Jean Baker Miller Training Institute}

Over the years, we have seen direct evidence of the shift that happens when people dance together, specifically when they dance together to address a shared concern. Recent research has attempted to unpack why and how this is so. But even before the neuroscientists got onto the idea of shared purpose through movement, the sociologist Emile Durkheim identified what he called "collective effervescence." Olaveson, in his 2001 essay, states: 
Durkheim explains, the "force of the collectivity is not wholly external; it does not move us entirely from outside. Indeed because society can exist only in and by means of individual minds, it must enter into us and become organized within us"...According to Durkheim, the means by which the "social" becomes internalized lies directly in the experiences generated in the context of collective ritual. As he states, the "very act of congregating is an exceptionally powerful stimulant. Once individuals are gathered together, a sort of electricity is generated from their closeness and quickly launches them into an extraordinary height of exaltation." Collective ritual, therefore, "brings about a state of effervescence that alters the conditions of psychic activity." (p. 81)

Along with Durkheim, Olaveson further points out that the anthropologist Victor Turner asserted: "that communitas could develop through ritual...communitas...refers to a state of equality, comradeship, and common humanity, outside of normal social distinctions, roles, and hierarchies."

In 2012, Meekums described how dance/movement therapy (DMT) uses the idea of kinesthetic empathy to develop our attachments to each other:

Schermer (2010) points out the mirror is a useful metaphor when contemplating the immediacy with which we all react to each other's nonverbal communication. He also notes the embodied nature of empathic engagement and suggests that 'Like the mirror's reflection, the social brain-mind is in a constant "dance" with other brains. In his discussion of the discovery of mirror neurones, he observes that "There is a "motoric" dimension to empathy, attunement, and attachment. That we are "moved" by another has a literal connotation.' (p. 14).

Or, as Marylee Hardenbergh puts it: "If everybody speaks at the same moment, it just creates bedlam. However, if everybody moves together at the same time, that can create a sense of closeness and community; people will have a sense of shared purpose and empowered action."

That we humans are wired for such experiences to be meaningful is becoming more apparent. We are built for cooperation and for collective action.

Adolphs (2009) cites Tomasello in the article on the social brain: "The basic fact is thus that human beings are able to pool their cognitive resources in ways that other species are not [is]...made possible by a single very special form of social cognition, namely, the ability of individual organisms to understand conspecifics as beings like themselves who have intentional and mental lives like their own." (p. 1)

And when conspecifics synchronize: "Humans spontaneously synchronize to a broad range of stimuli including interaction partners. Moreover, in recent years much evidence emerged that social synchronizing is not limited to motor processes but includes the activity of the brain and other bodily systems allowing dyads or groups of individuals to become something like a super-organism." (Hoehl, Fairhurst, \& Schirmer, 2021, p. 6) 
Each Global Water Dance, therefore, has the potential to become a super-organism, a force for shift to happen in the community.

\section{Education/Pedagogy}

Global Water Dances is part advocacy and part education. The pedagogy of Global Water Dances involves bringing a group of people together-sometimes these are trained dancers; sometimes they are simply community members who are game to learn a dance and to share their stories of water, water issues, water access, and thenco-learning and co-creating a performance that is inherently an educational experience, one that is progressive, constructivist, and democratic. Rooted in Laban's modern dance education, the progressive approach to education involves key learning strategies, including co-creation, transfer of learning across domains, and group engagement.

The dance occurs in informal, community-based settings but also occasionally in formalized settings with dance teachers and teaching artists working in both general and arts-focused schools, sometimes in collaboration with other educators, including teachers of science and visual arts. Often in such projects, the boundaries between students and teachers are blurred, decision-making is horizontal, not based on hierarchical structures allowing for coming together in a common purpose.

Such experiences were inherent in Laban's movement choirs and developed and demonstrated with his colleagues and students. They were all working together, co-creating theoretical ideas and structures, making the invisible visible, and claiming the spaces in nature as partners in the dance.

Along this line of thought, in the documentary film, Ripples and Reflections, Dr. Adesola Akinleye says: "I think dance changes things...so a space is changed by having dance and people moving in it." The sites where the dances happen are significant spaces. As an arts education experience, the phenomenon of reclaiming the spaces where water and dance exist together creates agency and a sense of purpose.

\section{Networking with Environmental Agencies}

The agency developed and reclaiming of space is not enough to create changes in policy, however. In 2019, we created the Site Impact Fund in order to encourage partnerships between local dance artists and local agencies and organizations that address local water issues.

Highlights from 2019 include the following:

- Ursula Carrascal in Callao, Peru partnered her organization, Asociación Cultural Minaq Ecodanza with the environmental organization: Vida Instituto para la Protección del Medio Ambiente. In the final report of the project, Carrascal states:

As part of the GWD day an environmental speech was organized in the beginning of the event. This was led by VIDA and Minaq 
Ecodanza. It also had contributions by TV Program Te Quiero Verde de Huacho, el Vivero Los Eucaliptos and the Asociacion de Propietarios de la Caleta Vidal. We have organized two clean ups (one on the beach, one in the wetland closest to the ditch of the town Caleta Vidal) so far. Through these clean-ups, statistics have been gathered on the types and quantities of waste.

- Cibele Sastre in Porto Alegre, Brazil partnered with AGAPAN (Associação Gaúcha de Proteção ao Ambiente Natural) to address a coming coal mine in the area. We had more than a hundred people sharing in the performance and gathering information. We started a network of sharing information about the coal mine and quality of Guaiba's water. Many people said that after the performance they felt invited to take more care about water issues, stop buying products that pollute. We found out that people that live in the neighborhood where we danced are not worried about the environmental impact of Mina Guaiba. Fishermen community representatives are convinced that Mina Guaiba will bring jobs and prosperity for the Region. We believe that the local people who assisted us in the performance and speech are the ones in charge of the space we used and have the opportunity to change people's minds after hearing how the mine will be dangerous for their fishing and drinking water and how it will cause sickness.

- In Taiwan, Feng Jiang from the organization, Life Holds No More, partnered with the Culture Office of Cizai Pijun to highlight the value of the black mud for fostering rich nutrients for the rice paddies nearby. The greatest achievement of this performance was to show that dance can also be one of the mediums and that people should be willing to approach environmental issues in more ways. We will continue to collaborate with the Culture Office of Cizai Pijun and use their ongoing Zhuoshui River Water Culture Survey as sources of creativity. Furthermore, we will perform in the Zhuoshui River area so that local people can feel the vitality of the river again.

- Shahid Mallick in Bangladesh: "For the ritual dance we followed the traditional folk dance of indigenous groups. For the local dance our performance focused on water abundance and how it's become scarce due to mismanagement. During the event a Water Aid representative talked about water need and why it's important to conserve water i.e. river, ponds and lakes. A local elected representative, union chairman, talked about the local river and mentioned that they appreciated GWD coming forward and joining in this event with local organization."

- Diya Moeller in Hyderabad, India: "The greatest impact our performance had on our community was the awareness of water conservation and water scarcity. We wanted to concentrate on teaching the material in a way that it is easily graspable and replicable for further generations. The impact created is a stepping stone for a greater consciousness." 


\section{Indigenous Knowledge and Ritual}

One of the major takeaways from the ten-plus years of this project is that the movement choir is but a version of what is ancient and long-understood wisdom: that dancing together is critical to community empowerment. In the ritual and local dance pieces, we see evidence of how each locale brings in local knowledge and ways of organizing, particularly in the non-hierarchical ways of true communitas. Although we have organized Global Water Dances as a committee of equals, we also see the challenges of contending with hierarchies designed to resist challenges to the status quo. At the same time, we see the power of dance to transcend hierarchies, particularly in the community-based practices of dance we see around the world. The value of ritual gatherings, of collective effervescence, of partnerships with policymakers and similarly focused organizations is clear. What the next ten years will bring is both unknown and challenging, but we can also see that it will be full of joy and commitment to the future of the planet and the children.

\section{Impact}

How do we measure the impact of Global Water Dances over the years?

We have conducted surveys and we can demonstrate the effect of the project on the audience is immediate. In one survey: 600 surveys were gathered from four continents, and some of the results were the following: $78 \%$ said the performance increased their interest in water issues and were inspired to take action; $68 \%$ were likely to make more efforts to conserve water in their personal use; $75 \%$ said they had a sense of community and that the dance helped them to see the location in a new way.

But we also know that surveys tell a snapshot story and may not result in any longer-term impact.

The stories we hear are more compelling. In a conversation with dance activist and global water dances site leader from New York, NY, USA, Lynn Neuman, she mentioned that Global Water Dances was an amplifier to her voice and there was an importance in a community of people who are activating others in different locations with the same goal, but at the same time, with different modus operandi that empowers others into action.

In Boca Raton, FL, USA, Nicole Perry shared: "The greatest impact this event had was that students, ages 11-16, participated in critical and creative thinking around water issues. They discussed the roles water plays in their lives, the concerns that they had re: water, and created poetry and reflections, as well as movement. For many students, this was the first time they used art to engage in an activist way."

Cynthia Pegado, in Buffalo River, NY, USA: "We raised awareness of the need for increased research on the effects of ingested environmental toxins and continued advocacy for clean water because research shows certain environmental exposures, for people with a genetic predisposition, increase risk of developing Parkinson's disease. PCBs have been found in relatively high concentrations in the brains of people who had Parkinson's disease. Our message is especially strong because our Global Water Dances performers are people with Parkinson's disease." 


\section{Implications Going Forward: A Model for Social Justice and Community Agency}

Over the next few years, the Global Water Dances project is poised to impact the ways in which communities address water issues as empowered constituents. We believe in the power of inclusive dance that is created, performed, and shared with those impacted by the water around them. As so many say, "Water is life." And life is what we all hope for, as we dance for water, everywhere, for everyone.

\section{Acknowledgements}

The authors wish to thank The Laban/Bartenieff Institute of Movement Studies, Cecilia Fontanesi, and Rebecca Barnstaple.

\section{Conflicts of Interest}

The authors declare no conflict of interest.

\section{About the Authors}

Natasha Alhadeff-Jones holds a Mastersin Dance Education from Teachers College, Columbia University and is a Certified Movement Analyst from the Laban/Bartenieff Institute of Movement Studies. She is currently training to become a Dynamic Embodiment ${ }^{\mathrm{TM}}$ Practitioner at the Dynamic Embodiment Somatic Movement Therapy Training program. She has taught all ages, in the fields of dance, environmental science and health education, in public schools, private schools and non-profit organizations in the U.S.A. and Switzerland. Most notably, in her roles as a contributor to the New York City Department of Education's Blueprint for Teaching and Learning in the Arts: Dance, Manager of School Programs at New York City Ballet, dance educator at Collège du Léman and Swiss Regional Lead of the Juilliard-Nord Anglia Performing Arts Programme, she designed curricula for students and facilitated professional development for teachers and administrators. In her current role as Artistic Director at the Sunkhronos Institute/MAPS Lab and serving on the international steering committee of Global Water Dances, Natasha promotes individual and collective transformations by teaching movement workshops, producing site-specific dance, and facilitating conversations, all informed by principles of dance education and ecosomatics.

Karen Bradley is currently the President of the Laban/Bartenieff Institute of Movement Studies, the Director of Research for the Institute, and the author of the book, Rudolf Laban, a volume of the Routledge Press' series on $20^{\text {th }}$ Century Performance Practitioners. She lectures and teaches around the world on Laban Movement Analysis. Bradley is also Emerita Associate Professor and former Head of Dance in the School of Theatre, Dance, and Performance Studies at the University of Maryland, College Park. She has applied the Laban/Bartenieff material to research in developmentallybased movement learning, the neuroscience of expressive movement, cross-cultural analysis of movement behavior, digital tool development, group behavior, and analysis 
of political leaders. She has also been investigating the efficacy and applications for over 3000 films at the Library of Congress that document cultural dance practices from the mid-20 $0^{\text {th }}$ century from around the world. Bradley lives in Musquodoboit Harbour, Nova Scotia, where she works as a dance therapist with seniors and children, people with Parkinson's, Alzheimer's, and related challenges.

Marylee Hardenbergh, a Certified Movement Analyst, a Board-Certified Dance Therapist, and a Licensed Independent Clinical Social Worker, is currently the Artistic Director of Global Site Performance and past Artistic/Executive Director of Global Water Dances. She created site-specific dances in Bosnia, Russia, Israel, Canada, Australia and the USA, receiving numerous grants and fellowships, including from the National Endowment for the Arts, the McKnight and Soros Foundations, and the Minnesota State Arts Board. She has taught in Melbourne, Ottawa and Athens as well as cities in the USA. Her work has been featured in Emergent Possibilities in Global Sustainability (2016), Dance Magazine, and in Site Dance: Choreographers and the Lure of Alternative Spaces (2009). She has been an Artist-in-Residence at the Center for Global Environmental Education at Hamline University in Minnesota. She was the keynote speaker at the 2015 American Dance Therapy Association conference. She loves to make simultaneous performances nationally and globally.

Vannia Ibarguen is an MFA Graduate in Dance from the University of Maryland, performer, choreographer, dance teacher, and Artistic Director of VIDA Vannia Ibarguen Dance Arts, a contemporary dance troupe. Her focus is on the interaction between performance and technology, and also the relationship between classical, contemporary and folk dance styles. She has received awards in United States, Peru, Argentina, Cuba, Colombia, and the NDEO Excellence in Education Award (National Dance Education Organization) in 2009.

Vannia is a recognized International Performing Arts consultant, collaborating since 2011 with Global Water Dances, an international initiative that raises consciousness on the critical need for safe drinking water, and now she is serving as Artistic Director. She was the Communications Manager of the Peruvian Dance Council, IT Consultant, and Magazine writer. Vannia also organizes "Encuentros de Pura Danza", an annual contemporary dance festival held in Lima, Peru since 2012, in collaboration with the Peruvian-American Cultural Institute (ICPNA).

\section{References}

Adolphs, R. (2009). The social brain: Neural basis of social knowledge. Annual Review of Psychology, 60, 693-716.

Green, M. (1986). The mountain of truth: The counterculture begins, Ascona 1900-1920. University Press of New England.

Hardenbergh, M., Bradley, K., \& Levinson, L. (2018). Global Water Dances: Embodying water solutions. In P. Godfrey \& D. Torres (Eds.), Emergent possibilities for global sustainability: Intersections of race, class and gender. Routledge.

Hoehl, S., Fairhurst, M., \& Schirmer, A. (2021). Interactional synchrony: Signals, mechanisms and benefits. Social Cognitive and Affective Neuroscience, 16, 5-18. Available: https://doi.org/10.1093/scan/nsaa024. 
Jordan, J. V., Walker, M., \& Hartling, L. M. (2004). The complexity of connection: Writings from the Stone Center's Jean Baker Miller Training Institute. Guildford Press.

Laban, R. (1975). A life for dance. Princeton Books.

Meekums, B. (2012). Kinesthetic empathy and movement metaphor in dance movement psychotherapy. In D. Reynolds \& M. Reason (Eds.), Kinesthetic empathy and movement metaphor in dance movement psychotherapy. Intellect Publ.

Olaveson, T. (2001). Collective effervescence and communitas: Processual models of ritual and society in Emile Durkheim and Victor Turner. Dialectical Anthropology, 26, 89-124. https://doi.org/10.102 3/A:1020447706406.

Schermer, V. (2010). Mirror neurons: Their implications for group psychotherapy. International Journal of Group Psychotherapy, 60, 486-513.

Tomasello, M. (1999). The cultural origins of human cognition. Harvard Univ. Press.

\section{Articles and Reports Cited}

Artist \& Climate Change. (2019). Dancing for fresh water everywhere. Available online: https:// artistsandclimatechange.com/2019/02/25/imagining-water-17-dancing-for-fresh-water-everywhere/ (accessed on 12 March 2021).

Flint School of Performing Arts. Available online: https://thefspa.org/global-water-dances/ (accessed on12 March 2021).

Global Water Dances. Available online: https:/globalwaterdances.org/global/our-impact/ (accessed on 12 March 2021).

Hamburg Open Online University. Available online: https://www.hoou.de/projects/ruvival-english/pages/ bwaise-uganda (accessed on 12 March 2021).

UCC. (2018). Global Water Dances: Following flows inside and alongside our bodies of water. Available online: https:/www.ucc.ie/en/fmt/theatre/news/global-water-dances-following-flows-inside-andalongside-our-bodies-of-water-.html (accessed on 12 March 2021).

Waterworld. (2017).Global Water Dances celebrate the importance of water across the globe. Available online: https:/www.waterworld.com/environmental/article/16223865/global-water-dances-celebratethe-importance-of-water-across-the-globe (accessed on 12 March 2021). 